\section{CHANGES OF CLIMATE}

Changes of Climate

Proceedings of the Rome Symposium organized by Unesco and the World Meteorological Organization. (Arid Zono Research-XX.) Pp. xii +488 . (Paris: Unesco; London: H.M. Stationery Office, 1963.) 28 francs; $40 s . ; 8$ dollars.

$\mathrm{T}$

HE study of climatic change is an attempt to reduce into some semblance of ordor changes in the Earth's climate on diverse scales in both space and time. It must consider the operation and effect of a large number of geophysical mechanisms, and involves the collation of rosults from many different scientific disciplines. It is an open secret that, perhaps because the subject is so complex, specious arguments have tended to go unchallenged and occasional dubious conclusions have found their way into text-books of climatology. A forum was obviously needed where ideas could be presented and criticized: the October 1961 symposium in Rome provided this. The volume under review contains the text of forty-five papers presented at the symposium together with a brief summary of the ensuing discussions.

Throughout the volume a laudable concern is shown for the physical significance of results, particularly those inferred from analyses of time series. There is a distinct tendency to adopt a more precise approach to the subject than hitherto. Also it should be notod that the problem considered was to assess whother any significant changes in climate can be rosolved from available data and to understand the mechanisms involved; it was not to attempt any prediction of future trends. The papers are divided into four main sections.

The first section deals with changes during the period of meteorological records. Most of these papers try to show the way in which the evidence falls into a pattern in which the physical significance depends on the combined results of several different variables. However, even when distinct tronds can be firmly established there was difficulty in interproting these in torms of what had happened to the atmospheric circulation. Section 2 is devoted to changes during late geological and early historical records. The net result hore is to show how various disciplines can combine to pose questions which meteorologists, without a quantitative theory of global elimate, find great diffculty in answering. Occasionally in the first two sections there is a tendency to consider mean atmospheric and mean oceanic circulations as though they are complete physical entitios in themselves rather than part of a statistical description of highly fluctuating flow-patterns. This is particularly noticoable when cause and effect are discussed: the importance of deviations from the average flow (eddies) wero sometimes forgotten. Thore are obviously many interrelated mechanisms going on that are extremely difficult to assess adequately in a qualitative way, and one is loft with the fecling that a moro precise treatmont along the lines indicated by the papers in the next section is urgently required.

Theories of changes of climate are the subjects of Section 3. Here there is a coll for an attempt to produce a rough model which can represent realistic seasonal variations; later the model might be usod to discriminate between likely and unlikely hypotheses. A pointer to the probable line of future attack is givon by two papors using a quantitative approach and extremely simple models to describe the effect of a hypothotical incroase in solar constant, and to test the validity of possible mechanisms of climatic change. Simple numerical techniques might well be profitably applied to some of the other theories advanced. Section 4 concerns the significance of changes of climate on vegetable cover, pattorns of land uso, geomorphological features, otc. The importance of variability of rainfall to agriculture in semi-arid rogions is emphasized, and the final paper stresses the practical implications of statistically insignificant changes in climate when a threshold, peculiar to the area and the crop, is crossed.

The whole publication is excollently produced in a paper-covered volume, but a summary of each paper in English as well as in French (vice versa for some papers) would have improved the presentation. For nearly 500 pages of valuable material the price is extremely low.

G. B. TuCker

\section{RUSSIAN APPROACH TO FISH ECOLOGY}

\section{The Ecology of Fishes}

By G. V. Nikolsky. Translatod from the Russian by L. Birkett. Pp. xv + 352. (London: Academic Press, Inc. (London), Ltd.; New York: Academic Press, Inc., 1963.) 758 .

7 THIS most stimulating book is especially welcome for three reasons. First, no other book covers the same ground, and it should be a very useful referenco work for both academic biologists and those concerned with fishery probloms. Secondly, this book and English translation make the great contribution of Soviet ichthyo. logists and ecologists available to the many who cannot read Russian. Thirdly, and in the long run perhaps most important, this book is to be wolcomed for its refreshingly unifying approach to biology.

Throughout the book one is aware of Prof. Nikolsky's appreciation of the unity of the organism and environment, and that it is the adaptive interactions to particular elements in the environment which ensure the develop. ment and existence both of the organism and of the spocies. It is made quite clear that ecological studios must be based on knowledge of the structure and functions of the organs, and that such studies, at all stagos of the life-cycle, make the only basis for rational fishery development.

The book is divided into three parts. In the first, Nikolsky considers "Interrelationships between Fishos and thoir Abiotic and Biotic Environment". It is here that the reader is most conscious of Nikolsky's continual awareness of the interchange betwoen the organism and all the many facets of tho environmont proceeding simultaneously: some factors having greater effect at one stage of the life-cycle and others at another, some having greater significance at one stage of the ovolution of the species and others at another, a continual flux and web, with continual interaction of the different factors. This interaction so often appears to be forgotten by those designing ecological experiments.

The abiotic rolationships considerod are the density and pressuro of water and adaptive changes of the swim bladders of different fish groups, water salinity and osmoregulatory mochanisms, gases in solution and adaptations for aorial respiration, the effects of temperature, light, sound, electrical and electromagnetic forces, and the fishes' reactions to bottom deposits and water movemonts. There is also mention of work on X-rays and radioactivity on fish, very relevant to the modern problom of dumping atomic waste. From experienco in high latitudes, atten. tion is directed to tho many ways in which ice affects fish.

The discussion on biotic relationships bogins with those which are intraspecific. This includes a useful summary of work on shoaling in fishes, of great importance for the design of fishing gear. When discussing interspecific relationships, Nikolsky comments on the difforencess in faunistic comploxos at different latitudes, the moro intensive prodator-prey relationships in lowor latitudes. with corresponding increase in the developmont of protective adaptations (such as great fecundity, care of young, armonr), and that lower-latitude fish tend to be more stenophagic. The interrolationships of fishes and othor organisms are then treated group by group, from 